College was in some financial straits, and it was agreed the Journal accounts might reasonably show a surplus rather than a deficit. In the event, and in the circumstances of the time, the Journal became a useful source of revenue. This seems entirely proper to me. The Journal acquired its prestige and readership as the result of generations of hard work by its honorary editorial teams. The College, which owns and administers the Journal, should profit from this historical asset.

BMB Did you enjoy your time as editor?

EHH I wish I could say yes, but I was so busy all the time. Perhaps it was my fault for being overconscientious.

BMB Should the arrangement of an unpaid honorary editor be continued?

EHH Perhaps: but if so, the editor should have had previous experience of journal or book production. I came with no such experience, and though this perhaps meant I came with a fresh mind, I made some mistakes from ignorance. Dr Crammer, my successor, had had quite a lot of experience and I expect this was a help to him. Our present editor has also had previous experience.

BMB Another approach might be for the Journal to be produced by a publishing firm.

EHH True. When I was editor, we were approached by a well-known firm to take over publication. I looked into the finances of such a deal, and although life would have been easier for the editor, it clearly wouldn't have been to the financial advantage of the College - at least not at that time, when we'd begun making a profit. But there's always something to be said for handing over publication to people who have special experience.

BMB How do you think the Journal compares with other journals in the field?

EHH I've often heard it said our Journal was one of the most respected of its kind-but that may be only self-praise or propaganda. Yet our Journal has certainly had a long and honourable history-age hasn't withered it - and I'd say we're preserving our honour satisfactorily.

BMB Have you read the very early issues of the Journal?

EHH I'm familiar with them. There were some extraordinarily able British psychiatrists in the 19th century who wrote excellent articles and fine textbooks - and of a literary standard which I'm not sure we've been able to match.

BMB And their subject matter?

EHH Not very different from today's, in essence. The early issues of a hundred years ago are full of sound stuff by the standards then. Nowadays there's more statistics, control and technical equipment, but I don't think there's been any real change in quality.

(The references will appear with Part II of this interview' which will be published next month.)

\title{
Medical Evidence in the Court of Protection
}

\section{Mrs A. B. Macfarlane, Master of the Court of Protection}

\section{Part I}

The Court of Protection, in 'carrying out its task of managing and administering the property and affairs of those who are incapable of managing for themselves, normally works by appointing a receiver to stand in the patient's shoes. The application for appointment of a receiver may be made through a firm of solicitors or by personal application to the Court. In either case, it needs to be supported by medical evidence, which is usually given on Form CP3. The Court is always conscious that its jurisdiction only extends to people who are incapable of managing their affairs by reason of mental disorder, so medical evidence there must be. (In rare cases, in an emergency, the Court is empowered to act even before receiving formal medical evidence, provided it has reason to believe that the person in question is suffering from mental disorder, but this power is exercised sparingly and only when its use is essential for the patient's protection.) It is an extreme step to deprive a person of his financial liberty and it must be reserved for cases where it is really necessary.

How does the medical certificate help the Court to decide a person's mental competence? First, it requires the doctor to give his name and address and his medical qualifications. (I need hardly say that the doctor may equally well be a woman, and the patient is even more likely to be a woman, but only the masculine pronoun is used in this article, for the sake of simplicity.)

Secondly, he is required to give details of the appointment he holds (if the patient is under his care by reason of being in, or attending at, a hospital or mental nursing home), or if the patient is at home or staying with relatives or friends, the doctor must state where the patient is living, that he is the patient's medical attendant and how long he has acted in that capacity.

Thirdly, the doctor must give the date on which he last examined the patient and must state, unreservedly, that in his opinion the patient is incapable by reason of mental disorder of managing and administering his property and affairs. The definition of mental disorder set out in section 1(2) of the Mental Health Act 1983 is one with which doctors will be familiar. However, one point needs particular emphasis: section 1(3) provides that nothing in the preceding sub-section shall be construed as implying that a person may be dealt with under the Act as suffering from mental disorder, or from any form of mental disorder 
described in the section, by reason only of promiscuity or other immoral conduct, sexual deviancy or dependence on alcohol or drugs. Consequently, in the latter cases, there must be some additional element of mental disorder present before the Court can consider itself as having jurisdiction, and the position will need to be set out fully in the certificate.

Next, and very important, is the question to the doctor as to the grounds upon which he bases his opinion. The marginal note requires him to 'state the nature of the mental disorder and reasons for the opinion expressed'. This speaks for itself, but the differing answers given by doctors (and the degree of their legibility) have to be seen to be believed. What the Court likes to have is a description (either in technical or non-technical language) of the specific disorder, with its name (if it has one), coupled with some idea of the severity of the affliction and of its consequences for the patient.

Question 4 on Form CP3 asks whether the patient is an informal patient or subject to compulsory detention, and if the latter, for what purpose and by what authority. Nearly all the Court's patients are informal patients.

The concluding questions cover a whole variety of topics and some are of great importance. For example, the doctor is asked the duration of the patient's existing disorder, whether he is capable of appreciating his surroundings, whether he could appreciate extra comforts, clothing or pocket money (and if so, at what weekly rate); how frequently he is visited, and by whom, his age, the state of his bodily health, his prospects of life and his prospects of mental recovery.

It is easy to see why these questions are of great relevance in helping to decide the course of future management of the patient's affairs; for example, important investment decisions may well be influenced by the answer to the question about the prospects of life. Occasionally, a doctor will appear to take the view that some of the questions asked are irrelevant or inappropriate, but when the matter is explained further, there is usually no problem in getting the missing answers. (The form may be at fault in failing to make clear why particular questions are being asked.)

When proceedings in the Court of Protection begin, the doctor may be requested not only to complete Form CP3, but also to serve the prospective patient with notice of the application, to give the patient the opportunity of sending to the Court objections or observations as regards the making of an order or the identity of the person proposed as receiver. Service by a doctor is effected by his delivering the notice of proceedings to the prospective patient, and leaving it with him. The doctor then has to complete Form CP7 (certifying that he has effected service) by inserting his name, address and medical qualifications, stating when and where he served the notice and then dating and signing the form and returning it to the solicitors who asked him to carry out the task. The notice is usually handed to a patient but it would also normally be considered to have been duly 'delivered' to the patient if it were laid under his hand or shown to him and then placed on his bed or bedside table; he is not required to pick it up and read it for himself before he can be treated as having been properly served.

The Court of Protection does have power to dispense with service of the notice of proceedings on the grounds: (a) that the patient is incapable of understanding the notice; (b) that service would be injurious to his health; or (c) for some other good reason. However, it is normally unwilling to exercise its power to allow service to be omitted because the Court regards it to be of fundamental importance that a person's financial liberty should not be taken away from him without his being given the fullest opportunity to object. Many patients have lucid intervals or days when they are better able to understand what is happening to them, and on one day they may be able to grasp the meaning of what is going on, even though on the next they may fall back into confusion. It should also be remembered that it is better to try and explain an application to a patient at a time when he has the opportunity of having his say (however irrational he may be) than leaving him to discover, perhaps in a lucid interval some while later, that his affairs are being dealt with under a Court order which he knows nothing about and upon which his views were not even sought.

Nevertheless, if there are cases where service will be, in a doctor's clinical judgement, harmful to the patient, or completely futile (for example, when the patient is in a coma, or has been severely mentally impaired all his life) evidence to this effect should be supplied to the applicant or his solicitors so that they can apply for service to be dispensed with.

The Bulletin (February 1983, 7, 34-35) published a list of guidelines for medical officers concerning certificates of incapacity relating to the 1959 Act, and although this Act has since been replaced by the 1983 Act, most of the guidelines remain extremely valuable and worth consulting.

\section{Part II}

At some time during the management by the Court of Protection of a patient's affairs, a doctor's opinion may be sought as to whether the patient is capable of making a valid will, or, as legal jargon usually has it, whether he is of testamentary capacity. It is sometimes a surprise to the layman to discover that a person may be incapable of managing his property and affairs, as a result of mental disorder, and yet may be well enough to give instructions to a solicitor to prepare a will; but that is the position in law. Testamentary capacity is generally considered to be present if three questions can be answered in the affirmative: (a) Does the patient understand what a will is? (b) Does he have a reasonable idea of the amount of money and property which is going to pass on his death? (c) Does he realize who would or would not normally be expected to benefit by his death, even if he would choose to make some other arrangement?

Sometimes the initiative in will-making comes from the patient, sometimes from a beneficiary, sometimes from the legal advisers of the patient or receiver and occasionally from the Court of Protection itself. As soon as the matter 
starts being considered, the first thing to be decided is whether the patient is of testamentary capacity, and it is the patient's own doctor, or perhaps the consultant who is treating him, who is expected to provide evidence in answer to these three questions.

Usually a special examination takes place at which, by means of questioning or testing, the doctor establishes to his own satisfaction the extent of the patient's understanding. Usually the patient's solicitor can let the doctor have particulars, before he sees the patient, of the actual situation as to the patient's assets and family circumstances. But if no solicitor is involved, or the necessary information is not otherwise available, the Court will give details to the doctor on a confidential basis; he is then better able to judge the extent of the patient's understanding.

As an aside, the problem of keeping professional confidences is one which, quite rightly, often troubles medical practitioners; they are naturally unwilling to divulge information and records relating to patients who have not given consent for this to be done. By way of reassurance, if it is the Court of Protection which is seeking the information, it is lawful to comply with the request, because the Court has a statutory power to make such enquiries as it thinks fit as to any dealing with the patient's property before the start of the proceedings in the Court and as to the mental capacity of the patient at the time of the dealing, and has general power to make or cause to be made any other inquiries which it may consider necessary or expedient while the patient is within its jurisdiction 'for the proper discharge of [the Court's] functions'. The definition of 'patient' includes a person who is alleged to be, or who the Court has reason to believe may be, incapable, by reason of mental disorder, of managing and administering his property and affairs. If a medical practitioner received an enquiry from the Court and failed to answer it, he could (in theory, at least) be served with a summons to attend the Court and give the information by way of evidence there (although happily this is not a situation which has arisen, in my experience). If other ethical problems arise at any time, the Court would be only too glad to give guidance in specific cases.

Returning to will-making, if a doctor forms the opinion that a patient has testamentary capacity, he may so certify and the Court will then authorize the preparation of the will by the solicitors concerned. The doctor who found the patient to be of capacity will be asked to act as one of the witnesses of the will; this is a precaution which may well avoid a legal dispute after the patient's death as to the validity of the will.

In any case of doubt, a doctor would be well advised to refuse to give an opinion in favour of capacity. The situation will then be that the Court is able to request one of the Lord Chancellor's Medical Visitors to make a visit and to report on the patient's capacity, or lack of it. If, in the end, testamentary capacity cannot be established, and if for some reason it would be undesirable or unjust for the estate to pass in accordance with the rules of intestate succession or under the terms of a will made by the patient before his illness, then the Court has power to make a 'statutory' will for the patient. The Master exercises this power after a summons has been issued and a hearing has been held, at which the interested parties may attend or be represented.

One other occasion on which a doctor may be asked by the Court of Protection to provide evidence is when a patient applies to come out of the Court's care and to be restored to the management of his own property and affairs. This procedure is called an application for an order 'determining' (that is, bringing to an end) the proceedings in the Court. An order determining proceedings can only be granted if there is clear medical evidence that the patient has recovered from whatever disease he was subject to while he was within the Court's jurisdiction (or any supervening disease). The doctor will be shown the original evidence before being asked about the present position.

Whether a patient is now once again able to manage his affairs can be a very difficult question to answer. It is comparatively straightforward if, for example, the original disorder was acute confusion, as a result of physical neglect, malnutrition or something of that kind, and the treatment given in hospital has led to considerable physical improvement, with consequent restoration of mental powers. This is a situation which is easily described and leaves little doubt in a practitioner's mind. However, there are examples where a patient was considered incapable because he had suffered some organic brain damage (usually in an accident). That organic damage will continue to be present and yet the patient may, over a period of time, so adapt to it as to regain his capacity to look after his own finances; but the point when he can be certified to have recovered sufficiently may be very hard to identify.

The converse situation may also arise; there may be incapacity without any ascertainable organic damage and without any measurable loss of intellectual functions. Particularly in cases of hypomania or schizophrenia, there may be elements of lack of insight and impaired judgement that are of great relevance in deciding upon financial competence, and which have to be taken into account in certifying fitness to manage. However much a patient may yearn to resume control, it is not fair to him (nor, incidentally, to his family or the world at large) to bring the Court's involvement to an end too soon.

Again, if a doctor has any doubt in his mind, it is safest to withhold a certificate and to explain fully the reasons. The Court can then, in borderline cases, obtain a further opinion from one of the Lord Chancellor's Medical Visitors.

Sadly, so many of our patients are elderly and chronically demented that comparatively few orders determining proceedings are sought, but applications are always welcomed, and so are the helpful opinions so often given to the Court by medical practitioners on these and other occasions. The Court would be quite unable to function without the help it receives from the medical profession in so many ways. 